\title{
DURABILITY OF MITRAL VALVE REPAIR FOR DEGENERATIVE DISEASE
}

\author{
A. Marc Gillinov, MD \\ Delos M. Cosgrove, MD \\ Eugene H. Blackstone, MD ${ }^{\mathrm{a}, \mathrm{b}}$ \\ Ramon Diaz, MD \\ John H. Arnold, MD \\ Bruce W. Lytle, MDa \\ Nicholas G. Smedira, MD \\ Joseph F. Sabik, MD \\ Patrick M. McCarthy, MD \\ Floyd D. Loop, MD
}

Background: Degenerative mitral valve disease is the most common cause of mitral regurgitation in the United States. Mitral valve repair is applicable in the majority of these patients and has become the procedure of choice. Objective: This study was undertaken to identify factors influencing the durability of mitral valve repair. Patients and methods: Between 1985 and 1997, 1072 patients underwent primary isolated mitral valve repair for valvular regurgitation caused by degenerative disease. Repair durability was assessed by multivariable risk factor analysis of reoperation. It was supplemented by a search for valve-related risk factors for death before reoperation. Three hospital deaths occurred $(0.3 \%)$; complete follow-up (4152 patient-years) was available in 1062 of 1069 hospital survivors (99.3\%). Results: At 10 years, freedom from reoperation was $\mathbf{9 3 \%}$. Among 30 patients who required reoperation for late mitral valve dysfunction, the repair failed in $\mathbf{1 6}(\mathbf{5 3 \%})$ as a result of progressive degenerative disease. Durability of repair was adversely affected by pathologic conditions other than posterior leaflet prolapse, use of chordal shortening, annuloplasty alone, and posterior leaflet resection without annuloplasty. Durability was greatest after quadrangular resection and annuloplasty for posterior leaflet prolapse and was enhanced by the use of intraoperative echocardiography. Death before reoperation was increased in patients having isolated anterior leaflet prolapse or valvular calcification and by use of chordal shortening or annuloplasty alone. Conclusions: Repair durability is greatest in patients with isolated posterior leaflet prolapse who have posterior leaflet resection and annuloplasty. Chordal shortening, annuloplasty alone, and leaflet resection without annuloplasty jeopardize late results. (J Thorac Cardiovasc Surg 1998;116:734-43)
$\mathrm{D}$ egenerative mitral valve disease is the most common cause of mitral regurgitation in the United States. ${ }^{1-3}$ With the use of current techniques, up to $95 \%$ of degenerative mitral valves can be repaired. ${ }^{4}$ Several large studies confirm high rates of freedom from reoperation after mitral valve repair. ${ }^{2-7}$ However, information concerning risk factors for reoperation is scarce.

From the Departments of Thoracic and Cardiovascular Surgery and Biostatistics and Epidemiology, ${ }^{\mathrm{b}}$ The Cleveland Clinic Foundation, Cleveland, Ohio.

Read at the Seventy-eighth Annual Meeting of The American Association for Thoracic Surgery, Boston, Mass, May 3-6, 1998.

Received for publication April 24, 1998; revisions requested June 10, 1998; revisions received July 8, 1998; accepted for publication July 16, 1998.

Address for reprints: A. Marc Gillinov, MD, Department of Thoracic and Cardiovascular Surgery/F25, The Cleveland Clinic Foundation, 9500 Euclid Ave, Cleveland, OH 44195.

Copyright $@ 1998$ by Mosby, Inc.

0022-5223/98 $\$ 5.00+0 \quad \mathbf{1 2 / 6 / 9 3 1 2 0}$
Such information would aid in patient selection and choice of operative technique. Thus the purpose of this study was to identify factors influencing the durability of repair for degenerative mitral valve disease.

\section{Patients and methods \\ Patients}

Study group. From 1985 to January 1, 1997, 1072 patients with mitral regurgitation caused by degenerative disease underwent isolated primary mitral valve repair at The Cleveland Clinic Foundation. These were identified as follows. Initially, the prospective Cardiovascular Information Registry (CVIR) was used to identify all patients having surgery for mitral regurgitation. The patients' medical records were then reviewed in detail, both to select those having degenerative disease and to verify the prospectively acquired CVIR clinical data. The study group was further refined by excluding patients having concomitant coronary artery, aortic valve, or arrhythmia (maze) operations. Patients with tricuspid annuloplasty were retained.

Definition. Degenerative valve disease was considered to be 
present when the patient had mitral regurgitation resulting from leaflet prolapse or annular dilatation and pathologic findings at operation were consistent with degenerative disease. The diagnosis of degenerative mitral valve disease was confirmed by echocardiographic and surgical findings.

Patient characteristics. Mean age at repair was $58 \pm 12.5$ years; 198 patients $(18 \%)$ were 70 years of age or older. A total of $699(65 \%)$ were men. Nearly all $(96 \%)$ had moderate or severe mitral regurgitation. Eighty-four percent of patients were in New York Heart Association functional class I or II. Posterior leaflet prolapse resulting from posterior chordal rupture was the most common finding, present in nearly half of the patients (Fig 1). Calcification of the anulus or leaflets was present in $16 \%$ of patients.

Comorbid conditions included atrial fibrillation in 39\%, hypertension in $33 \%$, chronic obstructive pulmonary disease in $8 \%$, peripheral vascular disease in $5 \%$, and diabetes in $3 \%$.

Follow-up. Systematic CVIR follow-up every 2 years was supplemented by telephone interview with the patient or referring cardiologist, or both, for those alive at the time of the previous anniversary follow-up. Complete follow-up information was available in 1062 of 1069 hospital survivors (99.3\%). Four patients could not be traced beyond hospital discharge, and 3 patients had partial follow-up. Mean length of follow-up among survivors was $4.0 \pm 2.9$ years, ranging from 2 months to 11 years. Median follow-up was 3.4 years; $25 \%$ were followed up for 6 years or more.

Outcomes. Durability of mitral valve repair was assessed primarily by the event reoperation after valve repair. Secondarily, we investigated death before reoperation to ascertain whether valve-related factors may have been associated with some deaths, possibly also reflecting durability of mitral valve repair. For this event, patients were censored for death at the time of reoperation.

Other events investigated briefly were all-cause death, thromboembolism, bleeding, and endocarditis.

\section{Data analysis}

Freedom from events. Nonparametric, non-risk-adjusted estimates of freedom from events were obtained by the method of Kaplan and Meier. ${ }^{8}$ For each event, a parametric method was used to resolve the number of hazard phases, identify the shape of the hazard function, and estimate its parameters. ${ }^{9}$

Multivariable analyses of outcomes. The potential risk factors (variables) entered into the analysis of reoperation and death before reoperation are listed in Appendix A.

Exploratory analyses included correlation analysis, contingency table analysis of categoric variables, $t$ test of the continuous variables, stratified life-table analyses, and decile risk analysis of ordinal and continuous variables to determine possible transformations of scale. A directed technique of stepwise entry of variables into the multivariable risk factor model was then used. ${ }^{10}$ The $P$ value criterion for retention of variables in the final model was .05. Regression coefficients are presented \pm 1 standard error.

To better understand the nature of the risk factors, we performed a sequence of 3 analyses for each event. In the first,

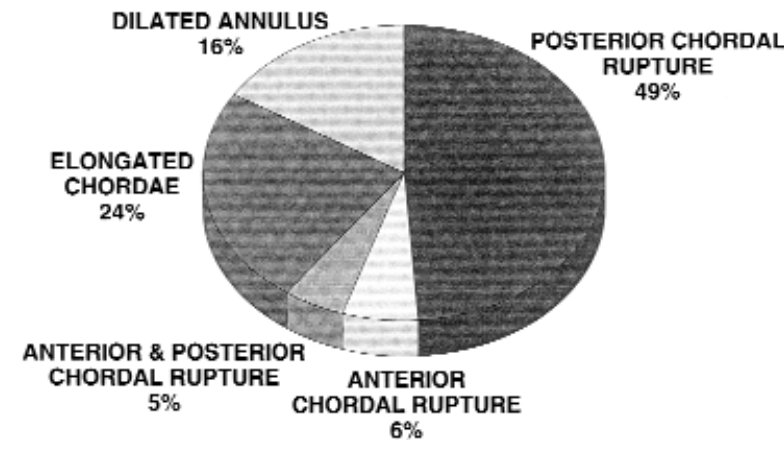

Fig 1. Pathologic anatomy of degenerative mitral valve disease $(n=1072)$.

all but repair variables were analyzed. In the second, all but valve pathology variables were examined. In the third, all variables were examined.

Nature and influence of risk factors. The influence of risk factors was explored in a risk-adjusted manner by constructing nomograms representing the solution of the parametric multivariable equation for specific values supplied for each risk factor, varying only 1 factor of interest.

Competing risks of events. In addition to its secondary use in searching for possible valve-related risk factors for death before reoperation, this event was also used to estimate the proportion of patients likely to require reoperation before dying. This is commonly called a competing risks analysis in the biostatistical community and actual versus actuarial analysis by Grunkemeier and colleagues. ${ }^{11-13}$ For this analysis, 3 mutually exclusive time-related end-states were defined: (1) alive without reoperation, (2) dead before reoperation, and (3) reoperation. The common time interval to each event was the time to the earliest event. Nonparametric competing risks estimates used the generalized Kaplan-Meier multiple-decrement method. Parametric risk-adjusted competing risks explorations were performed by means of the multivariable equations for each event, followed by numeric integration of the competing risks equations.

Presentation. Asymmetric 68\% confidence limits are comparable to \pm 1 standard error. In parametric depictions (smooth curves), these are represented by dashed lines. Nonparametric life-table estimates are presented with a symbol at the time of an event and vertical bars representing asymmetric $68 \%$ confidence limits. Periodically across time, the number of patients at risk are presented within parentheses.

\section{Results}

Surgical techniques and operative results. Overall, $88 \%$ of patients had an annuloplasty as part of the repair (Table I). Annuloplasty techniques varied during the period of this study. Techniques used included Cosgrove-Edwards annuloplasty band (Baxter Healthcare Corp, Irvine, Calif), Carpentier-Edwards classic 

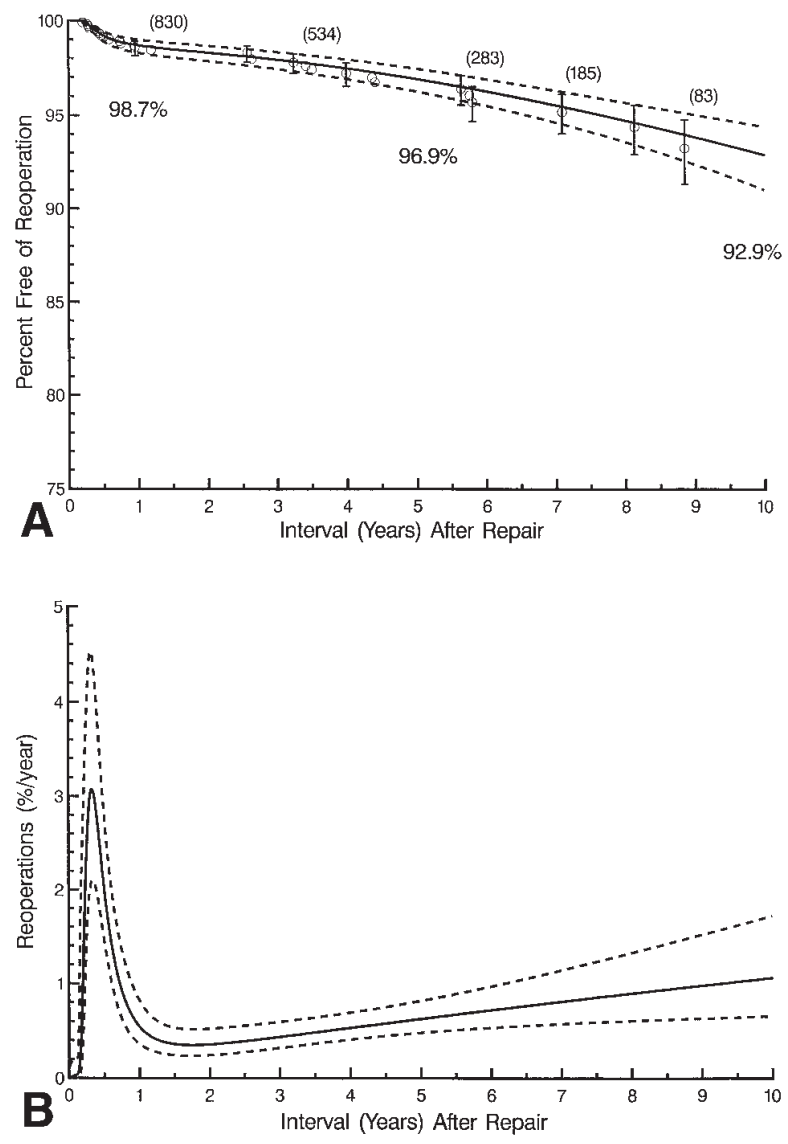

Fig 2. A, Freedom from reoperation after mitral valve repair (nonparametric and parametric estimates; see Patients and methods for details of the presentation). Note expanded vertical axis. B, Instantaneous risk (hazard function) for reoperation across time after mitral valve repair.

annuloplasty ring (Baxter Healthcare), and posterior pericardial plication with autologous pericardium or Periguard graft (Baxter Healthcare).

The most commonly performed operation was posterior leaflet quadrangular resection and annuloplasty (375 patients). Other frequent operations were posterior leaflet quadrangular resection, sliding leaflet repair and annuloplasty (136 patients), posterior leaflet quadrangular resection without annuloplasty (118 patients), and posterior leaflet quadrangular resection, chordal transfer, and annuloplasty (52 patients). Twenty-nine patients had annuloplasty alone. Twelve patients had concomitant tricuspid valve repair. Other combinations of mitral valve repair techniques were used in 391 patients. Intraoperative transesophageal echocardiography was used in 690 patients.

There were 3 operative deaths. All were attributable
Table I. Surgical techniques used for mitral valve repair

\begin{tabular}{lcc}
\hline Technique & No. & $\%$ \\
\hline Annuloplasty & 949 & 88 \\
Cosgrove-Edwards & 421 & 39 \\
Pericardial* $_{\text {Carpentier-Edwards }}$ & 313 & 29 \\
Posterior leaflet resection & 215 & 20 \\
Posterior sliding repair & 869 & 81 \\
Chordal transfer & 231 & 22 \\
Chordal shortening & 226 & 21 \\
Calcium debridement & 98 & 10 \\
& 72 & 7 \\
\hline
\end{tabular}

* Posterior pericardial annuloplasty was performed either with Periguard patch (306 patients) or autologous pericardium (7 patients).

Table II. Causes of failed mitral valve repair

\begin{tabular}{lcr}
\hline Cause of failed repair $(n=30)$ & No. & $\%$ \\
\hline Valve related & 17 & 57 \\
Progressive disease & 16 & 53 \\
Endocarditis & 1 & 3 \\
Procedure related & 9 & 30 \\
Ruptured chordae (previously shortened) & 4 & 13 \\
Suture dehiscence & 3 & 10 \\
Incomplete repair & 2 & 7 \\
Unknown & 4 & 13 \\
\hline
\end{tabular}

to cardiac failure. Of note, 2 of the 3 patients who died required a second period of cardiopulmonary bypass because of residual mitral regurgitation after initial repair. Postoperative morbidity included re-exploration for bleeding (47 patients, $4.4 \%$ ), respiratory insufficiency (24 patients, $2.2 \%$ ), myocardial infarction (10 patients, $0.9 \%)$, stroke (10 patients, $0.9 \%)$, and renal failure (8 patients, $0.7 \%$ ).

\section{Durability of the repair}

Outcome. Thirty patients required late reoperation for recurrent mitral valve regurgitation. Sixteen of these $(53 \%)$ had repair failure because of progression of degenerative valve disease (Table II). Thirteen patients (43\%) had reoperation within 1 year. At reoperation, 23 patients had mitral valve replacement and 7 had re-repair. All patients who had mitral valve re-repair survived the operation, and 1 patient undergoing replacement died. All survivors were in New York Heart Association functional class I at most recent follow-up.

Non-risk-adjusted freedom from reoperation. Ten-year freedom from reoperation was $92.9 \%$ (CL 91\%-94.4\%; Fig 2, A). The competing risks analysis revealed a similar "actual" freedom from reoperation because the prevalence of death before reoperation was low. The instantaneous risk of reoperation (hazard function) con- 

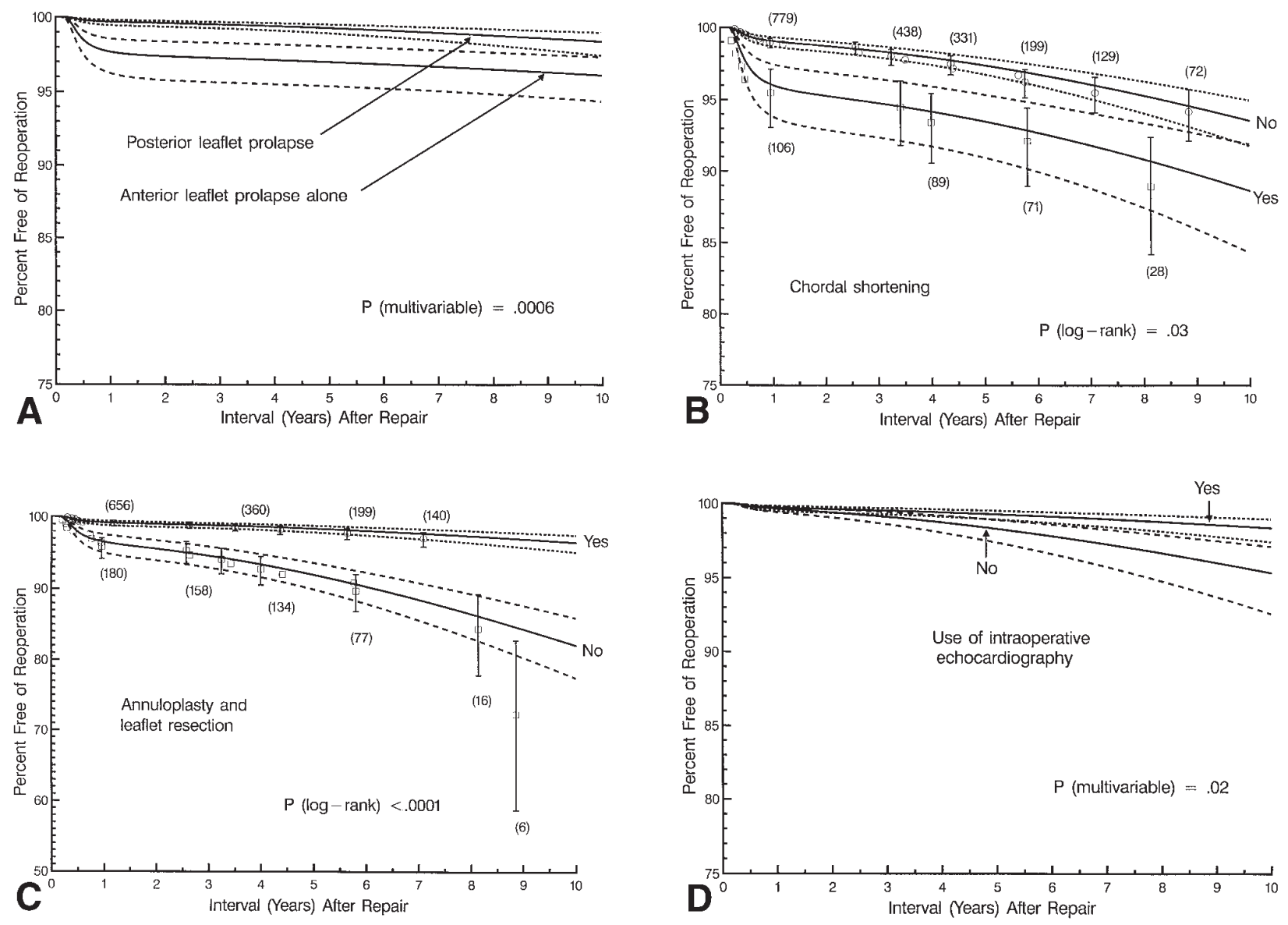

Fig 3. Influence of valve pathology and operative technique on freedom from reoperation. A, Anterior leaflet prolapse versus posterior leaflet prolapse. The presentation is a risk-adjusted comparison using the multivariable equation for a patient undergoing an operation with resection and annuloplasty without chordal shortening and using intraoperative echocardiography. B, Chordal shortening versus no chordal shortening. (The presentation is non-risk-adjusted, showing both nonparametric and parametric estimates.) $\mathbf{C}$, Posterior leaflet resection with annuloplasty (with or without sliding repair) versus all other repair techniques. D, Use of intraoperative echocardiography versus no intraoperative echocardiography.

Table III. Incremental risk factors for reoperation

\begin{tabular}{|c|c|c|c|c|}
\hline \multirow[b]{3}{*}{ Risk factor } & \multicolumn{4}{|c|}{ Hazard phase } \\
\hline & \multicolumn{2}{|c|}{ Early } & \multicolumn{2}{|c|}{ Late } \\
\hline & Coefficient $\pm S D$ & $\mathrm{P}$ value & Coefficient $\pm S D$ & $\mathrm{P}$ value \\
\hline \multicolumn{5}{|l|}{ Patient } \\
\hline \multicolumn{5}{|l|}{ Valve pathology } \\
\hline Prolapse of posterior leaflet* & $-2.1 \pm 0.63$ & .0006 & - & - \\
\hline \multicolumn{5}{|l|}{ Repair } \\
\hline Repair of coaptation & $3.9 \pm 0.65$ & $<.0001$ & - & - \\
\hline Chordal shortening & $1.35 \pm 0.64$ & .04 & - & - \\
\hline Ring annuloplasty + leaflet resection* & - & - & $-2.1 \pm 0.55$ & .0002 \\
\hline Use of intraoperative echo* & - & - & $-1.22 \pm 0.53$ & .02 \\
\hline Intercepts & -3.63 & & -4.87 & \\
\hline
\end{tabular}

$S D$, Standard deviation. Shaping parameter estimates: early phase $\delta=0, \rho=0.386, \nu=0, \mathrm{~m}=-1$; late phase $\tau=1, \alpha=1, \gamma=1, \eta=1.66$.

*Note: The negative sign on the coefficient indicates that the factor lessens the risk of reoperation. 

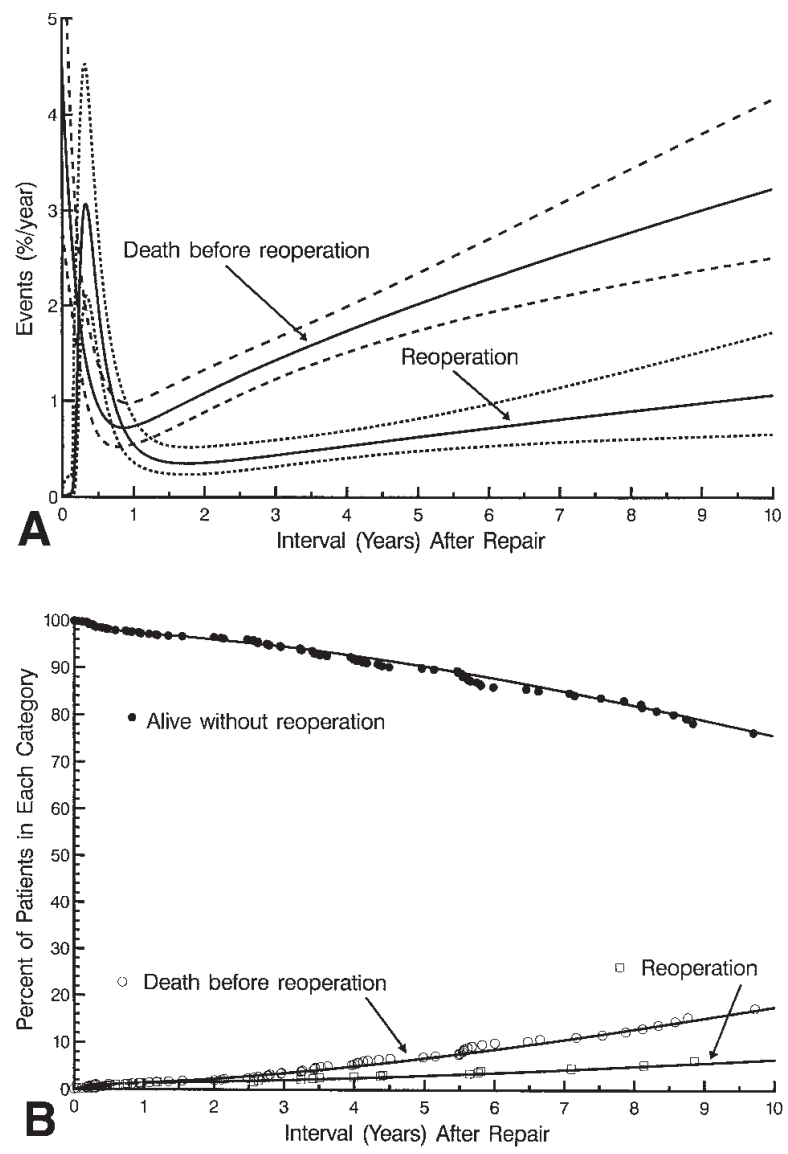

Fig 4. Death as a competing risk for reoperation. A, Hazard functions for death and reoperation, which compete to reduce the number of patients having reoperation. B, Number of patients (expressed as a percent of total) who remained alive without reoperation, died before reoperation, and experienced reoperation. The 2 hazard functions depicted in $\mathbf{A}$ act on the group alive without reoperation to populate the 2 outcome categories.

sisted of 2 hazard phases (Fig 2, B): There was a peaking early hazard phase in the first year after the operation followed by a slowly rising late hazard of reoperation.

Factors influencing repair durability. Incremental risk factors for reoperation differed depending on the interval between the primary operation and reoperation (Table III). Valve pathology influenced the risk of reoperation only during the early hazard phase. Patients with isolated anterior leaflet prolapse had an increased early risk of reoperation when compared with those with posterior leaflet prolapse (Fig 3, A); however, after 1 year, the instantaneous risk of valve failure was similar between patients with anterior leaflet prolapse and those with posterior leaflet prolapse. Valvular calcification had no impact on the risk of reoperation.

Repair techniques influenced the risk of reoperation in both the early and late hazard phases. The risk of early repair failure was increased by chordal shortening (Fig 3, B) and the requirement for additional sutures in the valve leaflets to increase leaflet coaptation. When compared with all other procedures, the technique of ring annuloplasty and leaflet resection was associated with decreased risk of reoperation in the late hazard phase (Fig 3,C).

Correspondingly, the risk of reoperation was increased in those patients who had chordal procedures without leaflet resection, annuloplasty alone, or leaflet resection without annuloplasty. Late durability was enhanced by intraoperative echocardiography (Fig 3,D).

\section{Death before reoperation}

Non-risk-adjusted estimates. Survival without reoperation was $82 \%$ (CL 79\%-84\%) 10 years after repair. The hazard function for death before reoperation was similar in pattern to that of reoperation in that 2 hazard phases were resolved, an early rapidly falling hazard that then rose steadily after the first year (Fig 4, A). These 2 hazard functions generate the risk-unadjusted proportion of patients alive without reoperation, dying before reoperation, and experiencing reoperation (Fig 4, B).

Factors influencing death before reoperation. Patients with isolated anterior leaflet prolapse or with valve calcification had an increased risk of death after operation (Table IV). In addition, patients who had chordal shortening or annuloplasty alone experienced an increased risk of late death. Additional factors associated with an increased risk of death were earlier date of repair, older age, atrial fibrillation, and renal disease. All had a minor effect on the estimates of 10-year prevalence of reoperation.

Other outcomes. Overall, there were 67 late deaths. Forty percent of late deaths were attributable to cardiac causes and $60 \%$ were noncardiac. The risk factors were identical to those for death before reoperation (Table IV) and differed trivially in magnitude. A summary of 1,5 , and 10 years' freedom from all outcomes studied after mitral valve repair is presented in Table V.

\section{Discussion}

Repair durability. Since the introduction of standardized techniques for mitral valve reconstruction by Carpentier, Duran, and others, mitral valve repair has become the surgical treatment of choice for mitral regurgitation. ${ }^{14-16}$ Numerous retrospective studies have demonstrated important benefits of mitral valve repair over mitral valve replacement. ${ }^{17-19}$ Mitral valve repair is most applicable to patients with degenerative mitral valve disease, with successful valvuloplasty possible in 95\% of such patients. ${ }^{2-4}$ Furthermore, it is in patients with degenerative mitral valve disease that repair has its greatest durability. With the longest follow-up to 
Table IV. Incremental risk factors for death before reoperation

\begin{tabular}{|c|c|c|c|c|}
\hline \multirow[b]{3}{*}{ Risk factor } & \multicolumn{4}{|c|}{ Hazard phase } \\
\hline & \multicolumn{2}{|c|}{ Early } & \multicolumn{2}{|c|}{ Late } \\
\hline & Coefficient $\pm S D$ & $\mathrm{P}$ value & Coefficient $\pm S D$ & $\mathrm{P}$ value \\
\hline \multicolumn{5}{|l|}{ Patient } \\
\hline \multicolumn{5}{|l|}{ Demographic } \\
\hline Older age & - & - & $0.065 \pm 0.0162$ & $<.0001$ \\
\hline \multicolumn{5}{|l|}{ Valve pathology } \\
\hline Isolated anterior leaflet prolapse & - & - & $0.85 \pm 0.38$ & .02 \\
\hline Annular or leaflet calcification & - & - & $0.77 \pm 0.29$ & .008 \\
\hline \multicolumn{5}{|l|}{ Comorbidity } \\
\hline Atrial fibrillation & - & - & $0.65 \pm 0.31$ & .03 \\
\hline Renal disease & - & - & $2.1 \pm 0.64$ & .001 \\
\hline Higher blood urea nitrogen & $0.052 \pm 0.0192$ & .007 & - & - \\
\hline \multicolumn{5}{|l|}{ Repair } \\
\hline Chordal shortening & - & - & $0.85 \pm 0.31$ & .006 \\
\hline Annuloplasty alone & - & - & $1.61 \pm 0.51$ & .002 \\
\hline \multicolumn{5}{|l|}{ Experience } \\
\hline Earlier date of repair & $-0.38 \pm 0.21$ & .006 & - & - \\
\hline Intercepts & -3.61 & & -10.7 & \\
\hline
\end{tabular}

$S D$, Standard deviation. Shaping parameter estimates: early phase $\delta=0, \rho=0.292, v=0, \mathrm{~m}=-1$; late phase $\tau=1, \alpha=1, \gamma=1, \eta=1.68$.

Table V. Events after mitral valve repair

\begin{tabular}{|c|c|c|c|c|c|c|c|c|}
\hline \multirow[b]{3}{*}{ Event } & \multirow[b]{3}{*}{ No } & \multirow[b]{3}{*}{ At risk (patient-years) } & \multicolumn{6}{|c|}{ Freedom } \\
\hline & & & \multicolumn{2}{|c|}{$1 y$} & \multicolumn{2}{|c|}{$5 y$} & \multicolumn{2}{|c|}{$10 y$} \\
\hline & & & $\%$ & $C L$ & $\%$ & $C L$ & $\%$ & $C L$ \\
\hline Death (all) & 70 & 4264 & 98.6 & $98.2-98.9$ & 93.0 & $92.1-93.8$ & 81 & $78-83$ \\
\hline Death before operation & 66 & 4152 & 98.6 & $98.2-98.9$ & 93.2 & $92.3-94.0$ & 82 & $79-84$ \\
\hline Reoperation & 30 & 4152 & 98.7 & $98.3-99.0$ & 96.9 & $96.2-97.5$ & 92.9 & $91.0-94.4$ \\
\hline Re-repair & 7 & 4152 & 99.7 & $99.5-99.8$ & 99.2 & $98.8-99.5$ & 98.6 & $97.9-99.0$ \\
\hline Replacement & 23 & 4171 & 98.7 & $98.3-99.0$ & 96.9 & $96.2-97.5$ & 92.9 & $91.0-94.4$ \\
\hline Thromboembolism* & 40 & 4081 & 98.8 & 98.4-99.0 & 96.2 & $95.4-96.8$ & 88 & $85-90$ \\
\hline Bleeding* & 6 & 4157 & 99.7 & $99.4-99.8$ & 99.4 & $99.0-99.6$ & 99.0 & 98.4-99.4 \\
\hline Endocarditis* & 3 & 4163 & 100 & $99.9-100$ & 99.7 & $99.4-99.8$ & 98.9 & $97.9-99.5$ \\
\hline
\end{tabular}

In no case was the risk (hazard function) constant across time; thus linearized rates have not been presented.

*Before valve replacement.

date, Deloche and associates ${ }^{4}$ found that 15 -year freedom from reoperation after mitral valve repair was 93\% in patients with degenerative disease.

Although repair durability is good in patients with degenerative disease, some patients will require late reoperation for recurrent mitral valve dysfunction. Causes of failed mitral valve repair may be classified as procedurerelated (rupture of previously shortened chordae, suture dehiscence, incomplete initial operation) or valve-related (progressive disease, endocarditis). Previous studies have documented a high proportion of procedure-related repair failures in patients with degenerative disease. ${ }^{20}$ This suggests that modification of operative technique might increase repair durability.
Previously identified risk factors for failure of mitral valve repair include advanced myxomatous changes of both leaflets, chordal shortening procedures, failure to perform an annuloplasty, residual mitral regurgitation at the completion of repair, New York Heart Association functional class III or IV, and performance of concomitant cardiac procedures. ${ }^{3,5,20-23}$ In the current analysis, both patient-related and surgical factors influenced the risk of reoperation on the mitral valve. However, patients with the most common pathologic findingposterior leaflet prolapse caused by chordal rupturehad the lowest risk of late reoperation. Correspondingly, the "standard" mitral valve repair of posterior leaflet quadrangular resection and annuloplasty had the greatest 
durability. This supports the results of Perier and coworkers. ${ }^{24}$ Failure to add an annuloplasty to posterior leaflet resection increased the risk of late reoperation. However, the type of annuloplasty (Cosgrove-Edwards, Carpentier-Edwards, posterior pericardial plication) did not influence repair durability.

Other specific repair techniques had an impact on repair durability. As we have demonstrated previously, chordal shortening increased the risk of late reoperation. ${ }^{20,21}$ Shortened chordae tend to rupture at the site of insertion into the papillary muscle trench. ${ }^{21}$ In addition, the requirement for additional leaflet sutures to increase local leaflet coaptation increased the risk of reoperation. Annuloplasty alone was also associated with a higher risk of reoperation. Finally, intraoperative echocardiographic guidance decreased the risk of late reoperation.

Late mortality. Although several studies document long-term survival after repair of degenerative mitral valves, most of these series include patients undergoing concomitant coronary artery bypass grafting., ${ }^{2,3,5,6}$ The presence of coronary artery disease may have an important impact on late survival, obscuring the "natural history" after isolated mitral valve repair. Nonetheless, in such series the 10-year survival is generally about $80 \% .^{2,3,5,6}$ Deloche and colleagues ${ }^{4}$ reported a 15 -year survival of $71 \%$ in patients undergoing primary isolated mitral valve repair for degenerative disease. In the latter series, approximately half of late deaths were valverelated. Similarly, important aortic valve abnormalities may jeopardize late survival, and we have not included patients with multiple valve disease in our study.

Previous studies provide little insight into risk factors for late mortality after mitral valve repair. In our study, we were particularly interested in exploring the possibility that risk factors related to the mitral valve might emerge that could reflect hidden additional repair failure. Both specific valve disease and specific surgical techniques increased the risk of death. These factors were among those that increased the risk of reoperation. Thus using valve reoperation as the sole indicator of valve repair durability may underestimate repair failure.

Limitations. The primary purpose of this study was to identify factors influencing the durability of mitral valve repair. We have used mitral reoperation as the primary indicator of durability. In addition, mitral valve-related risk factors for late death served as a secondary indicator of durability. Unfortunately, serial echocardiographic follow-up assessment of mitral valve function was unavailable in the majority of patients. Therefore the data did not allow identification of patients who had recurrent mitral regurgitation but did not undergo reop- eration, precluding an assessment of durability based on both reoperation and recurrent mitral regurgitation.

This series excluded, by design, patients with additional cardiac disease. Therefore results of this study may not be extrapolated to patients undergoing mitral valve repair in association with treatment of coronary artery disease, aortic valve disease, or other coexisting conditions.

Inferences concerning repair of degenerated mitral valves. Our results suggest several conclusions concerning surgical technique for repair of the degenerative mitral valve. Intraoperative echocardiography should be used routinely to assess the mechanism of valve dysfunction and the results of valve repair. Posterior leaflet quadrangular resection should be accompanied by an annuloplasty. Anterior leaflet prolapse should be corrected by techniques other than chordal shortening. In this series, chordal transfer did not increase the risk of repair failure, and previous studies demonstrate that it is a durable technique for treatment of anterior leaflet prolapse. ${ }^{21,25,26}$ Other techniques for correction of anterior leaflet prolapse might include use of artificial chordae and anchoring the free edge of the anterior leaflet to the posterior leaflet. ${ }^{27-29}$ Data comparing these techniques to chordal transfer are currently unavailable. Therefore we currently favor chordal transfer for correction of anterior leaflet prolapse.

\section{Conclusions}

This study has identified specific risk factors influencing durability of mitral valve repair for degenerative mitral regurgitation. The most durable repairs are obtained in patients with isolated posterior leaflet prolapse; these patients should be treated by quadrangular leaflet resection and annuloplasty. Chordal shortening increases the risk of reoperation and late death and should be supplanted by other techniques to correct anterior leaflet prolapse. Annuloplasty alone should rarely be used to correct mitral regurgitation in degenerative valves. Intraoperative echocardiography should be used routinely to guide repair and assess operative results.

We thank Judy Borsh, RN, Karen Mrazeck, and the other members of the thoracic and cardiovascular research team for their efforts in assembling and verifying the clinical data and performing the follow-up. Data management and preliminary statistical analyses were performed by Kristopher Arheart, $\mathrm{PhD}$, and Penny Houghtaling, MS, of the Department of Biostatistics and Epidemiology, Cleveland Clinic Foundation.

\section{REFERENCES}

1. Cosgrove DM. Mitral valve repair in patients with elongated chordae tendineae. J Card Surg 1989;4:247-52.

2. Reul RM, Cohn LH. Mitral valve reconstruction for mitral insufficiency. Prog Cardiovasc Dis 1997;39:567-99. 
3. David TE, Armstrong S, Sun Z, Daniel L. Late results of mitral valve repair for mitral regurgitation due to degenerative disease. Ann Thorac Surg 1993;56:7-14.

4. Deloche A, Jebara VA, Relland JYM, Chauvaud S, Fabiani JN, Perier P, et al. Valve repair with Carpentier techniques: the second decade. J Thorac Cardiovasc Surg 1990;99:990-1002.

5. Cohn LH, Couper GS, Aranki SF, Rizzo RJ, Kinchla NM, Collins JJ Jr. Long-term results of mitral valve reconstruction for regurgitation of the myxomatous mitral valve. J Thorac Cardiovasc Surg 1994;107:143-51.

6. Galloway AC, Colvin SB, Baumann G, Esposito R, Vohra R, Harty $\mathrm{S}$, et al. Long-term results of mitral valve reconstruction with Carpentier techniques in 148 patients with mitral insufficiency. Circulation 1988;78(Suppl):I97-105.

7. Alvarez JM, Deal CW, Loveridge K, Brennan P, Eisenberg R, Ward M, et al. Repairing the degenerative mitral valve: ten- to fifteen-year follow-up. J Thorac Cardiovasc Surg 1996;112:238-47.

8. Kaplan EL, Meier P. Nonparametric estimation from incomplete observations. J Am Stat Assoc 1958;53:457-81.

9. Blackstone EH, Naftel DC, Turner ME Jr. The decomposition of time-varying hazard into phases, each incorporating a separate stream of concomitant information. J Am Stat Assoc 1986;81: 615-24.

10. Baskerville JC, Toogood JH. Guided regression modeling for prediction and exploration of structure with many explanatory variables. Technometrics 1982;24:9-17.

11. David HA, Moeschberger ML. The theory of competing risks. New York: Macmillan; 1978. p. 45-56.

12. Grunkemeier GL, Anderson RP, Miller C, Starr A. Time-related analysis of nonfatal heart valve complications: cumulative incidence (actual) versus Kaplan-Meier (actuarial). Circulation 1997; 96(Suppl):II70-3.

13. Kalbfleisch JD, Prentice RL. The statistical analysis of failure time data. New York: John Wiley; 1980. p. 163-88.

14. Carpentier A. Cardiac valve surgery-the "French correction." J Thorac Cardiovasc Surg 1983;86:323-37.

15. Duran CMG. Perspectives in reparative surgery for acquired valvular disease. Adv Card Surg 1993;4:1-23.

16. Cosgrove DM, Chavez AM, Lytle BW, Gill CC, Stewart RW, Taylor PC, et al. Results of mitral valve reconstruction. Circulation 1986;74(Suppl):I82-7.

17. Enriquez-Sarano M, Schaff HV, Orszulak TA, Tajik AJ, Bailey KR, Frye RL. Valve repair improves the outcome of surgery for mitral regurgitation: a multivariate analysis. Circulation 1995;91: 1022-8.

18. Akins CW, Hilgenberg AD, Buckley MJ, Vlahakes GJ, Torchiana DF, Daggett WM, et al. Mitral valve reconstruction versus replacement for degenerative or ischemic mitral regurgitation. Ann Thorac Surg 1994;58:668-76.

19. Perier P, Deloche A, Chauvaud S, Fabiani JN, Rossant P, Bessou JP, et al. Comparative evaluation of mitral valve repair and replacement with Starr, Björk, and porcine valve prostheses. Circulation 1984;70(Suppl):I187-92.

20. Gillinov AM, Cosgrove DM, Lytle BW, Taylor PC, Stewart RW, McCarthy PM, et al. Reoperation for failure of mitral valve repair. J Thorac Cardiovasc Surg 1997;113:467-75.

21. Smedira NG, Selman R, Cosgrove DM, McCarthy PM, Lytle BW, Taylor PC, et al. Repair of anterior leaflet prolapse: chordal transfer is superior to chordal shortening. J Thorac Cardiovasc Surg 1996;112:287-92.
22. Fix J, Isada L, Cosgrove D, Miller DP, Savage R, Blum J, et al. Do patients with less than "echo-perfect" results from mitral valve repair by intraoperative echocardiography have a different outcome? Circulation 1993;88(Pt 2):39-48.

23. Fernandez J, Joyce DH, Hirschfeld U, Chen C, Laub GW, Adkins $\mathrm{MJ}$, et al. Factors affecting mitral reoperation in 317 survivors after mitral reconstruction. Ann Thorac Surg 1992;54:440-8.

24. Perier P, Stumpf J, Götz C, Lakew F, Schneider A, Clausnizer B, et al. Valve repair for mitral regurgitation caused by isolated prolapse of the posterior leaflet. Ann Thorac Surg 1997;64:445-50.

25. Sousa Uva M, Grare P, Jebara V, Fuzelier JF, Portoghese M, Acar $\mathrm{C}$, et al. Transposition of chordae in mitral valve repair: mid-term results. Circulation 1993;88(Pt 2):35-8.

26. Salati M, Moriggia S, Scrofani R, Santoli C. Chordal transposition for anterior mitral prolapse: early and long-term results. Eur J Cardiothorac Surg 1997;11:268-73.

27. Fucci C, Sandrelli L, Pardini A, Torracca L, Ferrari M, Alfieri O. Improved results with mitral valve repair using new surgical techniques. Eur J Cardiothorac Surg 1995;9:621-7.

28. Zussa C, Polesel E, Da Col U, Galloni M, Valfré C. Seven-year experience with chordal replacement with expanded polytetrafluoroethylene in floppy mitral valve. J Thorac Cardiovasc Surg 1994;108:37-41

29. David TE, Bos J, Rakowski H. Mitral valve repair by replacement of chordae tendineae with polytetrafluoroethylene sutures. J Thorac Cardiovasc Surg 1991;101:495-501.

\section{Appendix A: Variables included in multivariable analyses of risk factors for death and reoperation} Demography

Age

Sex

Pre-repair studies

New York Heart Association functional class

Chronic heart failure

Emergency surgery

Mitral valve disease

Prolapse of anterior leaflet

Prolapse of posterior leaflet

Rupture of chordae to anterior leaflet

Rupture of chordae to posterior leaflet

Elongation of chordae to anterior leaflet

Elongation of chordae to posterior leaflet

Annular calcification

Leaflet calcification

Annular dilatation

Left ventricular function

Grade of left ventricular dysfunction

History of myocardial infarction

Left ventricular hypertrophy

Cardiac comorbidity

Preoperative atrial fibrillation

Number of coronary systems with greater than $50 \%$ stenosis

Family history of coronary artery disease

Noncardiac comorbidity

Diabetes

Hypertension

Cerebrovascular accident

Peripheral vascular disease

Chronic obstructive pulmonary disease 


\author{
Renal failure \\ Blood urea nitrogen \\ Repair \\ Date of repair \\ Use of annuloplasty \\ Type of annuloplasty \\ Leaflet resection \\ Sliding leaflet repair \\ Chordal transfer (anteroanterior, posteroanterior, \\ anteroposterior) \\ Chordal shortening \\ Chordal resection \\ Repair of residual defect in leaflet coaptation \\ Use of intraoperative echocardiography
}

\section{Discussion}

Dr Lawrence H. Cohn (Boston, Mass). This is an outstanding paper by one of the premier mitral valve surgical units in the world. It summarizes an enormous experience, with superb statistical treatment courtesy of Dr Blackstone.

I agree with a great deal of what you say, particularly with regard to the annuloplasty ring. The contributions by Carpentier, Duran, and most recently by Dr Cosgrove of your institution, where an annuloplasty ring is used, have standardized and made reproducible the mitral valve repair operation the world over for floppy valve disease.

We presented a paper before this Association about 4 years ago in which we suggested that not using a support ring leads to a higher dysfunction rate. Your second point in this paper is that using chordal shortening techniques, particularly the trench technique in which you incise the papillary muscle and insert the chordae, leads to a higher dysfunction rate, particularly for anterior leaflet abnormalities. In 1991 we began to use the polytetrafluoroethylene* chorda technique, which was first suggested by Dr David, Dr Frater, Dr Zussa of New York, and Dr Treviso. In this situation we believe less is more. I know you used the "flip-over" technique, that is, using the posterior leaflet for anterior leaflet rupture. I would like to know what you do if you have a perfectly normal posterior leaflet and purely anterior leaflet prolapse. Do you still flip over part of the normal leaflet of the mitral posterior leaflet and use it as the support for the anterior leaflet?

I think the reason the ring is necessary-and every one of us has gotten a competent valve with complex floppy valves - is that often the anulus is very distorted and this leads to further dysfunction. Would you please comment on that point?

Finally, I would like to mention some of the insights we have gained in a small experience with the use of polytetrafluoroethylene chordae for primarily anterior leaflet disease. We no longer incise and remove a part of the anterior leaflet; we would prefer to use polytetrafluoroethylene chordae to both papillary muscles. In this situation we believe less is

*Gore-Tex tissue; registered trademark of W. L. Gore \& Associates, Inc, Elkton, Md. more. It is particularly efficacious in minimally invasive mitral valve repair.

Dr Gillinov. Thank you for your comments. You noted Dr Blackstone's contributions, and I should say that without him much of this analysis would not have been possible.

You commented on 2 general repair techniques: first, the use of a ring annuloplasty to reinforce the repair and remodel the anulus. We support this concept. Our results agree with yours, demonstrating that if a posterior leaflet resection is done without the use of a ring, the durability of the repair is jeopardized. Specifically, if posterior leaflet prolapse is treated with a posterior leaflet resection and ring annuloplasty, the freedom from reoperation at 10 years is $97 \%$. Failure to use the ring results in only $90 \%$ freedom from reoperation.

You also raised the question of the treatment of anterior mitral leaflet prolapse, a challenge that has been met successfully over the past 10 years. Currently, our preference is to use chordal transposition techniques, either transfer of a chord with a piece of leaflet from the posterior leaflet to the anterior leaflet or of a secondary anterior leaflet chord to the unsupported free edge of the anterior leaflet. However, as you noted, several groups, including yours, have had excellent experience with polytetrafluoroethylene chordae, and this might also be a good solution to that problem. We do not practice anterior leaflet resection. Of note, Alfieri recently described a technique of attaching the free edge of the anterior leaflet to the posterior leaflet to correct anterior leaflet prolapse. This may be another solution to the problem of anterior leaflet prolapse.

Dr Meredith L. Scott (Orlando, Fla). During this period of time, what types of rings did you use and what type of repair technique? In the subset of patients that had the ring only, did you evaluate left ventricular function or dilated cardiomyopathy?

Dr Gillinov. During the time period of the study, the type of ring varied. The first 200 or so patients received a Carpentier-Edwards ring. Thereafter, about 300 patients had a posterior pericardial plication of the anulus generally using a Periguard graft. The last 400 or so patients have had a Cosgrove-Edwards ring. We analyzed the ring type for its effect on durability of repair and found no difference in durability based on annuloplasty type. However, failure to use an annuloplasty ring did decrease repair durability.

You asked about the patients who had annuloplasty alone as a repair technique for degenerative disease. This series included only 29 such patients. These were not patients with cardiomyopathy; these were patients who underwent a single repair technique. In fact, they may have needed a leaflet resection or addition of other techniques because annuloplasty alone emerged as a risk factor for late repair failure.

Dr Tirone E. David (Toronto, Ontario, Canada). I was intrigued by your findings that anterior leaflet prolapse was an independent predictor not only of death but also of reoperation. It tells me that something has to be done about that. We have not done as many cases as the Cleveland Clinic surgeons, but we have done some 600 cases and we presented part of our series at this meeting last year. Anterior leaflet 
prolapse was not a predictor of poor outcome in our series. I think the difference is that we are very liberal users of polytetrafluoroethylene sutures to replace or reinforce any chorda that does not look right. Even if there is no leaflet prolapse but a chorda is flimsy, our tendency is to reinforce it with a fine polytetrafluoroethylene suture. This may explain why anterior leaflet prolapse did not affect our late results.

Dr Gillinov. Thank you for your comments. That certainly is a possibility. When we correct anterior leaflet prolapse using chordal transposition, it is difficult to reinforce the entire free edge of the anterior leaflet. Perhaps with the cre- ation of artificial chordae, it is possible to support more areas of the anterior leaflet and provide better support in certain instances of diffuse degenerative disease of the anterior leaflet.

Dr Radu C. Deac (Tirgu-Mures, Romania). In your followup, did you study the orifice area of this mitral valve? Can you comment on the quality of life after these operations?

Dr Gillinov. I do not have data on the orifice area of the mitral valve. I can tell you that annular dilatation was the principal pathologic abnormality in $22 \%$ of the patients, but I do not have echocardiographic data for the entire subset. I also do not have data on quality of life.

\section{Availability of Journal back issues}

As a service to our subscribers, copies of back issues of The Journal of Thoracic and Cardiovascular Surgery for the preceding 5 years are maintained and are available for purchase from Mosby at a cost of $\$ 16.00$ per issue until inventory is depleted. The following quantity discounts are available: $25 \%$ off on quantities of 12 to 23, and one third off on quantities of 24 or more. Please write to Mosby, Inc, Subscription Services, 11830 Westline Industrial Drive, St Louis, MO 63146-3318, or call 800-453-4351 or 314-453-4351 for information on availability of particular issues. If unavailable from the publisher, photocopies of complete issues may be purchased from UMI, 300 N Zeeb Rd, Ann Arbor, MI 48106, 313-761-4700. 